\title{
A Practitioner's Perspective On The Role Of A Third-Party Logistics Provider
}

Forrest B. Green, Radford University Will Turner, Radford University

Stephanie Roberts, Radford University

Ashwini Nagendra, Radford University

Eric Wininger, Radford University

\begin{abstract}
Most studies of logistics look at needs from the perspective of the hiring firm. This paper does that, but further examines the role of a third-party logistics provider by looking at services from the practitioner's perspective.
\end{abstract}

Keywords: Logistics, 3PL, Supply Chain, Third Party, Outsourcing, Non-asset Based

\section{INTRODUCTION}

ncreasing focus on global expansion in the marketplace has fostered greater attention on streamlining the supply chain management functions of business. Many companies choose to outsource part or all of their logistic functions to third parties in an attempt to achieve operational efficiencies within the supply chain. This also allows companies to concentrate on core business activities. Third-party logistics (abbreviated 3PL) providers are able to take over the supply chain functions of businesses and manage them better in many cases than what the companies could do on their own. This study presents advice on choosing a 3PL partner and examines the perspective of one major company heavily involved as a broker and provider of logistics services.

\section{THIRD-PARTY LOGISTICS OVERVIEW}

Typically, a core company providing services or products is considered the first party; the customer (or customers) the second party. A third-party, then, is a firm hired to do that which neither the first or second party desires to do. A third-party logistics firm is a firm that provides outsourced or "third party" logistics services to companies for some portion or all of their supply chain management functions. 3PL typically specializes in integrated warehousing and transportation services that can be scaled and customized to customer needs based on market conditions and the demand and delivery service requirements for their products and materials (SkjoettLarson, 2007). 3PL is evolving from a predominately transactional role to one that is more strategic in nature.

The 3PL industry evolved in the 1970's when during a time of expanding globalization and an increased use of information technology (Song \& Regan, 2001). These trends resulted in increased demands on firms, and possibilities for companies to operate more competitively in the marketplace. The first generation 3PL's (1970's1980's) offered services such as transportation, brokerage, and shipping. Second generation 3PL's (1980-1990) were mostly asset or non-asset based companies with increased service offerings. The third generation 3PL's (2000 onwards) were mostly web-based 3PL's with increased supply chain integration (Nemoto \& Koichiro, 2007).

\section{PL CHARACTERISTICS}

Some of the characteristics of 3PL's are that they perform a variety of outsourced logistics matters, provide customized services, and handle multiple activities. These may involve transportation, distribution, warehousing, material handling, inventory control, packaging and inspection (Bolumole, 2001). According to Sowinski (2005), some of the services offered by 3PL's in the current market are: 
- $\quad$ Dedicated contract transportation and transportation procurement.

- Inventory management

- $\quad$ Logistics management and consulting

- $\quad$ Freight audit and consulting

- $\quad$ Shipment tracking and tracing

- $\quad$ Reverse logistics and value added services

There are, of course, advantages and disadvantages to contracting with a third party in order to outsource portions of the supply chain function. The obvious downside is some loss of control when entrusting critical segments of a business to others. On the other hand, a company can benefit from the knowledge and expertise of specialized firms with assets and contacts unavailable otherwise. Some of the advantages and disadvantages of 3PL providers, according to Farris (2004), are set forth in Table 1:

Table 1

Advantages and Disadvantages of Using Third-Party Logistics Providers

\begin{tabular}{|l|l|}
\hline \multicolumn{1}{|c|}{ Advantages } & \multicolumn{1}{c|}{ Disadvantages } \\
\hline Cost reduction & Loss of control over the logistics function \\
\hline Improved efficiency, service and flexibility & Impact on in-house workforce \\
\hline Focus on core competency & More distance from clients- loss of personal touch \\
\hline Freeing up resources & Discontinuity of services of a 3PL provider \\
\hline Elimination of infrastructure resources & $\begin{array}{l}\text { Differences of opinion or perception of the service level of } \\
\text { the 3PL provider }\end{array}$ \\
\hline Risk- sharing & \\
\hline Better cash flow & \\
\hline Access to resources not available at one's own organization & \\
\hline
\end{tabular}

\section{CHOOSING A 3PL PROVIDER}

3PL relationships are on a contract basis typically involving a long-term commitment. The key to successful outsourcing relationships is having an organized process for selecting and communicating with potential 3PL vendors. A systematic approach will clarify the needs and alternatives and have a great impact on the final decision. According to Meritex Logistics (2007), there are at least nine steps that should be followed to successfully select a 3PL provider. With some variation, these are listed and described as follows:

- $\quad$ Form a cross-functional team- Choosing a 3PL provider should be a collaborative effort between various departments within a company (such as manufacturing, sales, marketing, finance, quality control, logistics, etc.). Bringing various departments together will allow the company to choose a 3PL provider that meets the needs of each department within the company.

- $\quad$ Set objectives- Objectives may include reducing costs, reaching new markets, a desire to concentrate on core competencies, or to be able to compete in a particular industry. Once a company defines its needs and wants, it can better choose a 3PL provider that will best suit those needs.

- Determine Customer Service Requirements- Since customers are the basic reason for a company's existence, their needs should be paramount when making a major decision. Customer service requirements should be delineated so they can be fulfilled effectively and efficiently. Identifying these needs can also be useful in forecasting future logistics services.

- Develop a List of Candidates- Online research can be used to locate 3PL providers that can suit one's logistics needs. 3PL providers can also be found in industry directories and through the International Warehouse Logistics Association (IWLA).

- $\quad$ Explore Interest Among 3PL Candidates-Before preparing a formal proposal, it is wise to check with 3PL providers to see if they would be willing to provide the services desired. A letter (or e-mail) which summarizes the company's situation and the logistics needs it seeks may be sent to promising 3PL 
candidates. This letter should also request information from the 3PL providers and the extent of their logistics capabilities.

- $\quad$ Solicit Requests for Proposals- After confirming interest from different 3PL providers, a company may then send requests for proposals (RFP's). The RFP's should provide a detailed outline of logistic services the company is seeking. Requirements that should be addressed include distribution, warehousing, transportation, and the extent of value-added services the company desires. It is important to go include sufficient detail so the 3PL providers know exactly what kind of logistic services are being sought.

- Visit the Prospective Provider's Facilities- Once the list of 3PL providers is narrowed down to four or five, each of their facilities should be visited by the cross-functional team. The team can survey each 3PL facility and rate them on various criteria. In addition to analyzing the 3PL's place of business, the crossfunctional team can get a chance to interact with management and employees and gain a better understanding of the work ethic and procedures of the 3PL's logistic services.

- $\quad$ Review Qualifications- Some of the data to be reviewed includes the RFP's and all aspects of each 3PL provider's business. These include financial information, strategic fit, general management philosophy, and the provider's track record of customer satisfaction in current and past business relationships.

- Choose the Best Candidate- Once all data are reviewed by the cross-functional team, it's time to choose the 3PL provider that will best meet the company's logistics needs. This begins a long term relationship calling for the cross-functional team to continually rate the effectiveness of the chosen 3PL provider to ensure future success and strategic fit with the company.

\section{INTERVIEW RESULTS}

During the course of this study, the authors interviewed a number of logistics providers and companies utilizing their services. For this paper, one interview was chosen as being fairly representative of others. It also includes particular insights not noted elsewhere that help relate the concerns and considerations of both contractor and 3PL provider. The interview looks at the other side, so to speak, by gaining the perspective of a major logistics company. This firm has operations in the United States, Canada, Mexico, South America, Europe, and Asia; employs 6,800 employees; and realizes close to $\$ 7$ billion in gross revenues. It is a non-asset based company in that it contracts with numerous carriers worldwide, those being fourth-party logistics providers (4PL's) in this context. Hence, the full range of logistic support activities serving 25 thousand customers is seen through this one company. The person who provided the information is the transportation sales executive for the company.

1. What tools and methodologies do companies use to optimize logistic providers?

Our customers look to us for global, multimodal (meaning by truck, rail, ocean, or air) planning and execution. They seek logistics providers that offer solutions to the challenges the ever-changing transportation presents.

2. What size companies benefit from logistic providers?

Any size company can benefit from logistics providers: smaller companies benefit from the vast knowledge and cost saving abilities a 3PL can provide. While larger companies can let us concentrate on our specialties to keep track of their complicated logistics problems. Larger companies can have many different challenges from many different plant locations; coordinating all of their needs can be a headache. A 3PL can concentrate on the task at hand without having to worry about the rest of the business, leaving the customer time to spend on its business goals.

3. Does your company provide the software needed for 3PL to clients and/or vendors?

Yes, we provide software that can integrate directly with the customers. This allows them to electronically send us load information and to view their current loads status. We also have a website for customers and carrier alike to use to seek business opportunities. 
4. What is the basis under which a 3PL is chosen and who the provider should be:

a. $\quad$ From previous experience?

b. References?

c. Allow a group of $3 P L$ 's to give presentations and then select from them?

3PL have to sell themselves to both customers and carriers. There are many reasons that make or break a 3PL from being used. It really depends on what the customer is looking for, some want the cheapest rates while others are willing to pay more for a higher level of service. The most important factor to consider when choosing a $3 \mathrm{PL}$ is whether or not they can provide a solution to match your challenges.

5. What is the main reason to use a third party logistics provider?

Service and flexibility. What sets us apart as a 3PL is our dedication to providing excellent customer service. That means offering problem prevention, communication, a proactive sense of urgency, attentiveness, and professionalism to every customer and carrier. Our non-asset-based philosophy accounts for some of this flexibility; by not having equipment, we are free to consider all options for the customer.

6. Do you control your clients' entire process or is it only certain functions in the chain?

Both depending on the freedom our customers give us really. Some only want us to find equipment for them; others look for us to handle everything from pickup to delivery, billing and loss prevention.

7. Do organizations view logistics outsourcing as a strategic response to environmental constraints or does it merely represent a tactical response for the purpose of reducing operational costs?

I would say that this really depends on the company. Some companies find it more economical to employ their own transportation and logistics needs. Others have outsourced due to the overwhelming cost of owning and maintaining a fleet of equipment. I would like to think that more companies are using 3PL's because of our high level of service and expertise. It's what we do and what we know that set's us apart and makes us the better option.

8. What measures do you have in place to ensure that the 3PL you choose has demonstrated expertise in this area, and can it supply proven performance based results?

When we source equipment to use for our customers transportation needs, we are very careful and thorough. We are trusting these companies with valuable cargo both money-wise and time sensitive. Any loss can be quite costly whether it's through product damage, production delays, or delays to the vendor. We select carriers with solid track records. We try to build solid relationships with the carriers we use to establish trust and ensure superior service.

9. What effect do 3PL's have on the structure and performance of supply chain flows?

3PL's offer superior service and industry knowledge. They can make the performance of the supply chain more efficient.

\section{CONCLUSION}

With the increasing focus of business expansion into the global market, companies need to have an extremely lean, efficient supply chain to achieve successful integration into new markets. 3PL providers can help provide services to these companies, but also assist the more localized companies looking to cut operational costs or focus on core competencies. There are many advantages to outsourcing logistics services to third parties. The amount of services being offered by these logistics providers continues to grow each year. Today, 3PL's are more than just transportation providers; they are becoming involved in the long-term strategic direction of their client companies. 
The key to successful outsourcing of logistics services lies in finding a 3PL provider that has the most strategic fit with the company's goals. An efficient way of selecting the proper 3PL provider is to follow the nine steps mentioned earlier. The most important step in selecting a 3PL provider is to ensure the decision is a collaborative one made by representatives of all departments within a company.

Companies have successfully used 3PL providers to handle their logistics needs, while 3PL companies such as that in the second interview have been leading the way in providing the service required. Although the future of the 3PL industry is somewhat uncertain, it can be assured that the increasing global demand and technological capabilities will lead to further integration between 3PL providers and companies alike.

\section{WORKS CITED}

1. Bolumole, Y. (2001). The Supply Chain Role of Third-Party Logistics Providers. International Journal of Logistics Management, Vol. 12 No. 2, pp. 87-102

2. C.H. Robinson website. Retrieved April 18, 2007, from http://www.chrobinson.com

3. Farris, B. (2004, March 16). Dedicated Contract Carriage. Presentation before the Food Marketing Institute. Retrieved April 1, 2007, from http://www.fmi.org/events/2004_Distribution/Outsourcing_Transportation.pdf

4. $\quad$ Meritex Logistics (2007). Selecting a 3PL Provider. Retrieved March 25, 2007, from http://www.meritexlogistics.com/selecting_a 3 pl.html

5. Nemoto, T.\& Koichiro, T. (2007) Advantage of Third Party Logistics in Supply Chain Management. Retrieved April 1, 2007, from http://www.cm.hit-u.ac.jp/katsudo/wp/WP_72.pdf

6. Skjoett-Larsen, T. (1999). Third Party Logistics- From an Interorganizational Point of View. International Journal of Physical Distribution and Logistics Management, Vol. 30 No. 2, pp. 112-127

7. Song, J. \& Regan A. (2001). Industries in Transition: Freight Transportation Intermediaries in the Information Age. Retrieved April 2, 2007, from http://www.metrans.org/outreach/confs/jiongmet01.ppt

8. Sowinski, L. (2005). Taking Advantage of Expanding 3PL Services. Retrieved April 9, 2007, from http://www.worldtrademag.com/CDA/Articles/3PL/ff6e07fc6aaf7010VgnVCM100000f932a8c0

\section{ACKNOWLEDGEMENTS}

Thank you to the following person for contributing his efforts to the creation of this document:

Michael Rose

Transportation Sales

C.H. Robinson Worldwide 
NOTES 